\title{
Protection efficacy of national wetland reserves in China
}

\author{
ZHENG YaoMin $^{1}$, ZHANG HaiYing ${ }^{1}$, NIU ZhenGuo ${ }^{1 *}$ \& GONG Peng ${ }^{1,2,3 *}$ \\ ${ }^{1}$ State Key Laboratory of Remote Sensing Science, Jointly Sponsored by Institute of Remote Sensing Applications, Chinese Academy of Sciences \\ and Beijing Normal University, Beijing 100101, China; \\ ${ }^{2}$ Ministry of Education Key Laboratory for Earth System Modeling, Center for Earth System Science, Institute for Global Change Studies, Tsing- \\ hua University, Beijing 100084, China; \\ ${ }^{3}$ Department of Environmental Science, Policy and Management, University of California, Berkeley, California 94720-3114, USA
}

Received August 10, 2011; accepted November 28, 2011

\begin{abstract}
Wetlands have the most abundant biodiversity, the highest carbon sequestration capacity, and the highest values for ecological services per unit area, of all the world's ecosystems. Practice has shown that establishing reserves is the most effective way of protecting typical ecosystems and their biodiversity, and saving rare or endangered wildlife. The Chinese government's policy is to protect wetland systems by establishing reserves that encompass a massive network of wetlands, including wetland nature reserves, internationally important wetlands, and wetland parks. Many are already established. The effect of protecting wetland nature reserves at the national level has not yet been reported. We used the latest database evaluating the protection value of wetland reserves, and remotely sensed wetland maps (1978-2008), developed by the same mapping specialists and based on the same classification system, and related environmental data, to evaluate the effects of protecting China's national wetland reserves over the last 30 years. We conclude that (i) the total area of wetland in the national wetland reserves has decreased over the last 30 years to $8152.47 \mathrm{~km}^{2}$, and just $8 \%$ of China's net decrease in wetlands; (ii) about $79 \%$ of the 91 national wetland reserves are in a poor condition. These are generally located around the Yangtze River, Eastern Coast, the Three Rivers Source, and Southwest China. Protection measures should be undertaken urgently in these areas. Only 15\% of national wetland reserves are under sound protection, and these are generally located in the upper reaches of the Songhua River; (iii) although $88 \%$ of national wetland reserves are primitive (relatively natural), implying that the site selection has been scientific, a high percentage of national wetland reserves show early warning signs of decline and require urgent attention; (iv) based on our evaluation of protection effects and pressures on ecology, we have made a priority list of national wetland reserves, and propose several protection strategies.
\end{abstract}

remote sensing, wetlands, protection, ecology, early warning signs

Citation: Zheng Y M, Zhang H Y, Niu Z G, et al. Protection efficacy of national wetland reserves in China. Chin Sci Bull, 2012, 57: 1116-1134, doi: 10.1007/s11434-011-4942-9

Wetlands have the highest ecological value per unit area on earth [1], the strongest carbon sequestration capability [2], and the greatest biodiversity protection significance [3-7]. Protecting wetlands and their biodiversity has attracted significant attention from the international community (http:// www.wetlands.org, 2010). However, the effectiveness of wetland protection has rarely been considered. There is a great need for quantitative assessment of wetland ecosystems to aid understanding of likely global environmental

*Corresponding authors (email: zhgniu@irsa.ac.cn; gong@irsa.ac.cn) change [8].

Through over 140 years of practice, the establishment of nature reserves has been shown to be the best method of protecting biodiversity, and an effective measure for maintaining the ecological security of a region [9]. Prior to 2008, there were $1.2 \times 10^{5}$ protected areas around the world, occupying about $2.1 \times 10^{7} \mathrm{~km}^{2}$ in total area (http://www.unepwcmc.org/wdpa/statistics, 2010), and accounting for $14 \%$ of the world's total land area.

There has been no agreement on the classification of the world's protected areas. After several rounds of discussion 
and revision by the International Union for Conservation of Nature and Natural Resources (IUCN) in 1969, 1972, 1978 and 1994, protected areas have been divided into 6 types, including Strict Nature Reserve (Ia), Wilderness Area (Ib), National Park (II), Natural Monument or Feature (III), Habitat Species management Area (IV), Protected Landscape/seascape (V) and Protected Area with sustainable use of natural resources (VI) (http://www.iucn.org, 2010).

Studies on nature reserve classification were carried out in China during the 20th century [10]. In 1993, the "Chinese Nature Reserves Classification and Ranking Principle" was published jointly by the former State Environmental Protection Agency and the State Administration of Technological Supervision, and this was accepted as a national standard (GB/T 14529-93) [11]. By consideration of the main protection roles, this document divided Chinese nature reserves into 3 categories and 9 types: the natural ecosystem class (forest, prairie and meadow, wilderness, interior wetland, and marine/coast), the wildlife class (wild animals and wild plants), and the natural vestige class (geological vestige and extinct organism vestige). Prior to 2011, China had established 614 wetland reserves [12,13], and 91 of these are national wetland reserves.

A wetland protection network has been established. This is made up of mostly wetland reserves, along with international important wetlands, wetland parks, special marine reserves, small wetland reserves and wetland multipurpose reserves. However, no report has evaluated the effects of wetland protection, or assessed the spatial distribution of China's wetland reserves.

Assessment of protection value refers to research into natural resources and the importance of nature reserves, including the relative diversity, rarity, representativeness, suitability, naturalness, and human disturbance of reserves $[13,14]$. Protection effect evaluation is comprehensive research into the levels of protection of national wetland reserves from the perspective of protection value, dynamic change, the expansion of species, and the functional zoning suggested by conservation biology, ecology, and nature reserve science.

There has been no appropriate definition of ecological security [15]. Some believe that ecological security is as important as national and economic security (http://www. cctv.com/news/ocus/story/story0423.html, 2010). Ecological security can be explained as comprising two aspects. First, degeneration of the ecological environment poses a threat to sustainable economic development; and second, public disaffection raised by environmental problems poses a threat to social stability $[15,16]$.

Combining remote sensing (RS) and geographic information system (GIS) has created a powerful analytical method for exploring the dynamics of wetlands and developing an influential model for change [17-20]. There is currently no literature relating to the effects of protecting wetlands at the national level because of the lack of data.

Zheng [13] completed maps of the boundaries of national wetland reserves, and suggested a ranked list of national and provincial wetland reserves based on 16 categories of wetland reserves across China, depending on their protection value.

Gong et al. [9] revised the wetland classification system suggested by Niu et al. [21] and completed wetland maps of China for the past 30 years based on remotely sensed data [22]. These wetland-related data have laid the foundations for assessment of the effectiveness of wetland protection at the national level.

We analyzed changes in wetland reserves and assessed the effects of protection and human pressure over the last 30 years, mainly by using wetland maps, national wetland reserve boundary data, protection value data, and related data.

\section{Methods}

\subsection{Data sources and preparation}

\subsubsection{Chinese wetland maps based on satellite data}

The Chinese wetland maps were developed primarily by manual interpretation [8,21], in which the narrowest river width was $90 \mathrm{~m}$ and the area of the minimum mapping unit was about $9 \times 10^{4} \mathrm{~m}^{2}$. Four different maps at $20 \mathrm{~m}$ (2008), $30 \mathrm{~m}$ (2000, 1990), and $80 \mathrm{~m}$ (1978) resolutions were resampled into maps with the same cell size $(240 \mathrm{~m} \times 240 \mathrm{~m})$ for comparative purposes.

\subsubsection{Database of wetland reserves}

Data for 182 wetland reserves were collected [23-26], the database for protection value evaluation of wetland reserves was established and distribution maps of wetland reserves were created. The websites of the nature reserve authorities were used for checking data and updating it in real time. For details see Zheng [13].

The distribution maps of wetland reserves were scanned, adjusted, and quantified based on the general plan of wetland reserves. Basic information about the reserves from scientific reports was input into an Excel spreadsheet and then loaded into a special database. Data from the "1:4000000 Chinese wetland distribution map" (State Forest Administration, 2003), the "1:4000000 Chinese river system distribution map" (https://219.238.166.215/mcp/index.asp, 2011), "the Chinese map" (Map Publishing House, 2010), "the remote sensing data of Beijing Smallsat", and "the announcement material on the website of the reserves authorities" were used as supplementary material for checking and analysis.

\subsubsection{Database of ecological pressure}

Charts of Chinese population density and land use were downloaded from the Internet (http://www.igsnrr.ac.cn/xxgx/ 200909/t20090904_2464203.html, 2011) and Chinese road, rail, and residential areas were taken from the China National 1:1000000 terrain database (State Administration of Surveying, Mapping, and Geoinformation, 2002). 


\subsection{Research methods and data processing}

Our methods for evaluating the effects of protection were based on the protection value, the measurement of wetland changes, wildlife population proliferation, and functional zone adjustment in wetland reserves. The habitats we studied included interior wetland reserves, marine/coast reserves, and some wild animals reserves. We subdivided the reserves of interior wetland into lacustrine wetlands, riverine wetlands, and palustrine wetlands.

\subsubsection{Evaluation of protection value}

When analyzing the actual situation of Chinese nature reserves, Zheng et al. [27] selected several indicators such as diversity, representativeness, rarity, naturalness, area suitability, vulnerability, and human threats, and put forward a systematic method for ecological evaluation. Following revision, this has been widely used as the accreditation standard for National Nature Reserves (http://sts.mep.gov. cn/zrbhq/pxbz/199904/t1999041585000.htm, 2011). However, the method excessively depends on expert evaluation with low quantitative levels, and neglects the unique characteristics of wetland reserves. Zheng et al. [13] established an indicator system to evaluate the protection values of wetland reserves; this is a quantitative evaluation of protection value of wetland reserves by category.

Based on the scientific investigation reports of 182 wetland reserves, the protection value of national wetland reserves was evaluated by coupling the analytic hierarchy process $[13,27,28]$, with expert consultation, and the quartile method. The wetland reserves indicator system mainly includes 5 series and 16 sets: lacustrine wetlands (permanent freshwater lakes and permanent saltwater lakes), riverine wetlands (permanent rivers, seasonal and intermittent rivers, and flood plains), palustrine wetlands (peatmire, herbaceous marshes, woody swamps, swamp meadows, pale springs, and oasis wetlands), marine/coast wetlands (mangroves, coral reefs, estuarine waters, shallow waters, seaweed deposits, intertidal wetlands), and wildlife (birds, fish, animals, amphibians, reptiles).

The indicator system of these series has 10 systematic indices: degree of endangeredness, representativeness, rarity, diversity, area suitability, human threats, tourism function, fish function, water function and land function. The system also used 32 indicators with different weights and grade intervals (for details see Zhang [13]); permanent freshwater lake reserves are an example.

(i) Degree of endangeredness reflects endangered species information that is the core value of wetland reserves.

(1) I1 The number of essential species. Essential species are species essential in the ecosystem; these are often the most endangered species. The IUCN Red List has been widely used globally, nationally, and regionally for endangered species risk assessment [29]. However, a risk assessment for the essential species in Chinese national wetland reserves has not been published. The selection of essential species should satisfy the requirements of the "IUCN Red List" [30] and the "China Endangered Animal Red Book" [31].

(2) I2 The population ratios of endangered species in reserves. Endangered species were selected from the list of national key protected species, the red list of Chinese species, the red book of Chinese endangered wildlife, the appendix of the Convention on International Trade in Endangered Species of Wild Fauna and Flora, the migratory bird protection agreement of Sino-Australian countries, the migratory bird protection agreement of Sino-Japanese countries, and the 15 key protected species of the State Forestry Administration.

(3) I3 The number of endemic species. The endemic species were also selected from the "IUCN Red List" [30] and the "China Endangered Animal Red Book" [31].

(ii) Representativeness reflects the ability of a wetland to represent national or basin levels; the amount of information about the homogeneity of nature reserves per unit area.

With reference to "the National Wetland Resources Investigation Technical Regulations" (State Forest Administration, 2009), continental territories were divided into 11 first order basins, 83 second order basins, and 225 third order basins. Based on the "Chinese Bay" book [32], the coast basin was divided into 4 second order basins and 13 third order basins for research convenience. The number of wetland reserves in each basin was calculated as follows: If a reserve belonged to only 1 basin it was counted as 1 ; if it crossed 2 basins it was counted as 0.5 ; if it crossed 3 basins, it was counted as 0.33 , and so on.

(iii) Rarity reflects the number of national key protected species in wetland reserves, including the number of national first order and second order species.

(iv) Diversity reflects the biodiversity conditions of the wetland reserves, including 7 indices; the number of vascular plant species, chordates, haloplankton, benthos, birds, habitat types and the population size of birds.

(v) Suitability reflects the scale and the quality of reserves, including 3 indices of the area of reserves, the proportions of core zoning and wetland areas.

(vi) Human threats reflect the intensity at which reserves were affected by human activities. Human threats included 2 indices, the population density inside reserves, and the population size of adjacent communities.

(vii) Tourism function was used as the index of annual environmental carrying capacity.

(viii) The annual catch was used to estimate fish resources in reserves.

(ix) Water quality and quantity was used to estimate water function in reserves.

(x) Cultivated area and area of reed swamp within reserves were used to estimate land function.

The protection value evaluation model used was as follows: 


$$
S=\sum_{i=1}^{n} W_{i} X_{i}
$$

where $S$ is the protection value index of China's national wetland reserves, $W_{i}$ is the synthesis weight, $X_{i}$ is the index value, $i$ is the serial number of the index.

\subsubsection{Evaluation of wetland changes}

We calculated the speed and the acceleration of wetland changes before and after the establishment of reserves. The formula used was as follows:

$$
\begin{gathered}
R=\Delta A / A, \\
\mathrm{~d} R=\left(R_{2}-R_{1}\right) /\left|R_{1}\right|,
\end{gathered}
$$

where $R$ is the wetland change rate in the reserve, $\Delta A$ is the total net variation value of the wetland in the reserve, $A$ is the area of the reserve, $R_{1}$ is the wetland change rate before the establishment of a reserve, $R_{2}$ is the wetland change rate after the establishment of a reserve, and $\mathrm{d} R$ is the variation in the former two.

\subsubsection{Evaluation of proliferation}

Considering the specialty of wildlife reserves, the evaluation index of wetland change was replaced by an evaluation index of expanding propagation and proliferation. The formula was as follows:

$$
L=\sum_{k=1}^{m}\left(N_{2}-N_{1}\right) / N_{1}\left(a_{2}-a_{1}\right)
$$

where $L$ is the rate of annual increase, $N_{1}$ is the number of endangered species when the reserve was established, $N_{2}$ is the number after the establishment of the reserve, $a_{1}$ is the year when the reserve was established, $a_{2}$ is the year after its establishment, $k$ is the serial number of endangered species in the reserve, and $m$ is the number of endangered species in the reserve.

\subsubsection{Evaluation of functional zoning adjustment}

With the enclosure of massive areas of wetland by the Chinese government, many local authorities promoted functional zoing adjustment of reserves in order to obtain the greatest commercial benefit, the foresight-lacking action damaged reserves' interests deviated from the spirit of the "Nature Reserves Rule", and seriously reduced the protection effects. We believe that changes to functional zoning should be minimal and that the total area of reserves should remain the same.

The function zoning adjustment index $D$ of wetland reserves was developed to include this aspect. The formula was as follows:

$$
D=\left|A_{2}-A_{1}\right| / A_{1},
$$

where $D$ is the functional zoning adjustment index, $A_{1}$ is the area of wetland reserve before adjustment, and $A_{2}$ is the area after adjustment.

\subsubsection{Determination of thresholds}

For the grade intervals for the evaluation indices of protection effects see Tables $1-4$. Tables 1,2 , and 4 are for wetland ecosystem reserves, while Tables 1, 3 and 4 are for wildlife reserves.

\subsubsection{Evaluation of ecological pressure}

First, a detailed list of pressures on the ecology of wetland reserves was established, initially based on the methods of the analytic hierarchy process. Ecological security pressure was based on three factors; land use, road traffic, and population, by assigning different weights to these indices (Table 5). Because plantations, orchards, and artificial pastures

Table 1 Grade intervals for the protection value evaluation index

\begin{tabular}{lcc}
\hline \multirow{2}{*}{ Grade } & \multicolumn{2}{c}{ Index of protective value } \\
\cline { 2 - 3 } & Wetland ecosystem reserves & Wildlife reserves \\
\hline Excellent & $66-71$ & $\geqslant 71$ \\
Moderate & $<66$ & $63-71$ \\
Poor & & $<63$ \\
\hline
\end{tabular}

Table 2 Grade intervals for the wetland change evaluation index

\begin{tabular}{lll}
\hline \multicolumn{1}{c}{ Grade } & \multicolumn{1}{c}{$R_{1}$ and $R_{2}$} & \multicolumn{1}{c}{ Remarks } \\
\hline Excellent & $R_{1}$ is negative and $R_{2}=$ Zero & Improvement \\
Excellent & $R_{1}=$ Zero and $R_{2}$ is positive & Improvement \\
Excellent & $R_{1}$ is negative and $R_{2}$ is positive & Improvement \\
Poor & $R_{1}$ is positive and $R_{2}=$ Zero & Deterioration \\
Poor & $R_{1}=$ Zero, and $R_{2}$ is negative & Deterioration \\
Poor & $R_{1}$ is positive and $R_{2}$ is negative & Deterioration \\
Excellent & $\mathrm{d} R \geqslant 10 \%$ & Improvement \\
Moderate & $-10 \%<\mathrm{d} R<10 \%$ & Almost invariant \\
Poor & $\mathrm{d} R \leqslant-10 \%$ & Deterioration \\
\hline
\end{tabular}

Table 3 Grade intervals for the proliferation evaluation index

\begin{tabular}{ccc}
\hline \multirow{2}{*}{ Grade } & \multicolumn{2}{c}{ Index of proliferation evaluation } \\
\cline { 2 - 3 } & Annual growth rate & Annual growth number \\
\hline Excellent & $10 \%$ & $\geqslant 10000$ \\
Moderate & $1 \%-10 \%$ & $1000-10000$ \\
Poor & $<1 \%$ & $<1000$ \\
\hline
\end{tabular}

Table 4 Grade intervals for functional zoning adjustment

\begin{tabular}{lcl}
\hline Grade & Index of functional zoning adjustment & \multicolumn{1}{c}{ Remarks } \\
\hline Excellent & 0 & Extremely reasonable \\
Moderate & $0-10 \%$ & Basically reasonable \\
Poor & $\geqslant 10 \%$ & Unreasonable \\
\hline
\end{tabular}


Table 5 Pressure indices and weight analysis of China's national wetland reserves

\begin{tabular}{|c|c|c|c|c|}
\hline System layer & Weight of system layer & Indicator layer & Weight of indicator layer & Synthetic weight \\
\hline \multirow{4}{*}{ Land use } & \multirow{4}{*}{0.40} & Urban and rural resident land & 0.55 & 0.22 \\
\hline & & Cropland & 0.25 & 0.10 \\
\hline & & Forestry land & 0.10 & 0.04 \\
\hline & & Grassland & 0.10 & 0.04 \\
\hline \multirow{6}{*}{ Traffic load } & \multirow{6}{*}{0.40} & Railway & 0.25 & 0.10 \\
\hline & & Expressway & 0.25 & 0.10 \\
\hline & & Major highway & 0.20 & 0.08 \\
\hline & & Secondary highway & 0.15 & 0.06 \\
\hline & & Cart track & 0.10 & 0.04 \\
\hline & & Lane & 0.05 & 0.02 \\
\hline \multirow{3}{*}{ Population pressure } & \multirow{3}{*}{0.20} & Population density & 0.50 & 0.10 \\
\hline & & Township & 0.30 & 0.06 \\
\hline & & Villages and mining sites & 0.20 & 0.04 \\
\hline
\end{tabular}

Table 6 Effective strength of pressure on the ecology within national wetland reserves

\begin{tabular}{clc}
\hline System layer & \multicolumn{1}{c}{ Indicator layer } & Grade of effective strength \\
\hline \multirow{4}{*}{ Land use } & Urban and rural resident land & Extremely strong \\
& Cropland & Strong \\
& Forestry land & Weak \\
& Grassland & Weak \\
\hline \multirow{4}{*}{ Traffic load } & Railway & Strong \\
& Expressway & Strong \\
& Secondary highway & Strong \\
& Cart track & Moderate \\
& Lane & Weak \\
Population & Population density & Unidentifiable \\
\cline { 2 - 3 } pressure & Township & Strong \\
& Villages and mining sites & Moderate \\
\hline
\end{tabular}

were also included in forests and grasslands, these were considered to put pressure on wetland reserves.

Second, the scale of pressure on the ecology of wetland reserves was divided into six levels (Tables 6 and 7). Each levels assigned different scores, the level of extremely strong, strong, moderate, weak, unidentifiable and none assigned $100,80,60,40,20$ and 0 , respectively.

The third step was to calculate the effect of ecological security pressure. Raster data such as land use and population density were spatially overlaid onto a map of wetland reserves in ArcGIS 9.3 (ESRI Inc.), and then averaged. The effect was divided into 6 levels (Tables 5-7). Land use included urban and rural residential land, cultivated land, forest, and grassland. The vector data such as transportation distribution, villages and towns, were also overlaid onto a map of wetland reserves. Their intersection was used to judge the strength of the effect (Tables 5 and 6); where there was no intersection, this meant that there was no effect.

The 4th step was to calculate the ecological security pressure index of wetland reserves. The formula was as follows:

$$
S_{n}=I_{m n} \times W_{m n}
$$

where $S$ is the value of ecological security pressure, $I$ represents the level of effect, $W$ represents the synthesis weight, $m$ is the serial number of the indicator layer, and $n$ is the serial number of the reserve.

Table 7 Grade intervals for strength of pressure effect

\begin{tabular}{|c|c|c|c|c|c|c|c|}
\hline & & \multicolumn{6}{|c|}{ Six levels } \\
\hline & & $\begin{array}{l}\text { Extremely } \\
\text { strong }\end{array}$ & Strong & Moderate & Weak & Unidentifiable & No \\
\hline \multirow{4}{*}{ Land use } & Urban and rural Residential land & {$[5,+\infty)$} & {$[1.5,5)$} & {$[0.5,1.5)$} & {$[0.1,0.5)$} & {$[0.05,0.1)$} & {$[0,0.05)$} \\
\hline & Cropland & {$[40,+\infty)$} & {$[15,40)$} & {$[10,15)$} & {$[5,10)$} & {$[1,5)$} & {$[0,1)$} \\
\hline & Forestry land & {$[50,+\infty)$} & {$[25,50)$} & {$[15,25)$} & {$[10,15)$} & {$[1,10)$} & {$[0,1)$} \\
\hline & Grassland & {$[60,+\infty)$} & {$[35,60)$} & {$[20,35)$} & {$[10,20)$} & {$[1,10)$} & {$[0,1)$} \\
\hline $\begin{array}{l}\text { Population } \\
\text { pressure }\end{array}$ & Population density (person $\mathrm{km}^{-2}$ ) & {$[250,+\infty)$} & {$[75,250)$} & {$[25,75)$} & {$[10,25)$} & {$[1,10)$} & {$[0,1)$} \\
\hline
\end{tabular}


The 5th step was to build an early warning rank system to show the pressure on the ecology of wetland reserves; based on a scientific definition and judgment of the ecological security pressure index, eco-security, and eco-insecurity.

Eco-security is defined as the stable, coordinated, permanent use of an ecosystem under three constraints; population, social economy, and ecology [22-24]. Eco-security indicates that a system maintains its organizational structure and resists coercion for development, while satisfying human demands for resources and maintaining ecological significance and health.

Eco-insecurity means that ecosystem functions are incomplete or abnormal, and its safety is threatened. The degree of threat can be categorized into three levels: yellow, orange, and red.

Criteria for determination of eco-security or eco-insecurity are difficult to find. We used only the 5 indices of urban and rural residential land, cultivated land, railroads, highways, and population density, for establishing eco-security standards. When the effects of these 5 indices are all moderate, and those of other indices are negligible, reserves were considered naturally primitive and relatively safe. In this case, the ecological security pressure index $=(0.22+0.10+0.10+$ $0.10+0.10) \times 60=37$ (Table 5). When the ecological security pressure index of a reserve is greater than 37 , this indicates eco-insecurity. Similarly, if the 5 indices are all strong or extremely strong, and the other indices are negligible, the ecological pressure indices would be 50 and 62, respectively; these are the thresholds for orange and red levels (Table 8 for details).

\section{Results and discussion}

\subsection{The basic situation of China's national wetland reserves}

At the end of May 2011, there were 91 national wetland reserves in mainland China, excluding any in Hong Kong, Macao, or Taiwan. These reserves covered $2.64 \times 10^{5} \mathrm{~km}^{2}$; approximately $2.5 \%$ of the area of China's land, and account for $29 \%$ of China's reserves by area. Provinces with five or more national wetland reserves are Heilongjiang, Jilin, Guangdong and Inner Mongolia (14, 8, 6 and 5 reserves, respectively). Those with 3 or 4 national wetland reserves are Hubei, Hainan, Shandong, Sichuan, Liaoning, Gansu, Anhui, Guangxi, Jiangsu, Henan, Qinghai, Tibet and Yunnan. There are
Table 8 Early warning ranks for pressure on ecology of wetland reserves

\begin{tabular}{lll}
\hline & Rank & Index of ecological pressure \\
\hline \multirow{2}{*}{ Eco-secure reserves } & Red reserves & $(62-100)$ \\
& Orange reserves & $(50-62]$ \\
& Yellow reserves & $(37-50]$ \\
Eco-insecure reserves & Primitive reserves & {$[0-37]$} \\
\hline
\end{tabular}

presently no national wetland reserves in Beijing and Shanxi.

Qinghai Province has the largest area of national wetland reserves: $1.57 \times 10^{5} \mathrm{~km}^{2}$, and $60 \%$ of the area of China's national wetland reserves. Tibet, Heilongjiang and Inner Mongolia all have around $1 \times 10^{4}-3 \times 10^{4} \mathrm{~km}^{2}$ of national wetland reserves, whereas Tianjin, Ningxia, Hubei, Shanghai, Jiangxi, Hebei, Guizhou, Guangxi, Fujian, Zhejiang and Hainan have $0-1000 \mathrm{~km}^{2}$.

Most of China's national wetland reserves were established between 1978 and 2000, with some established after 2000 , during a promotional period for national reserves. This was probably because China joined the international "Convention of Wetlands of International Importance Especially as Waterfowl Habitats" in 1992, and started a project called "Wildlife Protection and Nature Reserves Construction" in 2001. In 2006, this wetland project was included in the Eleventh Five Year Plan.

\subsection{Changes in protected wetlands}

The area of wetland reserve and the actual area of wetland in a reserve are two different concepts. The former describes the total area of reserves, generally staying unchanged, except when being merged with another wetland, extended or adjusted. However, the actual area of wetland in a reserve is often in a fluctuating state, depending on available water. In general, the area of wetland in a reserve is smaller than the area of wetland reserve.

The area of protected wetlands has shown a downward trend over the last 30 years, with a total net decrease of approximately $8152.47 \mathrm{~km}^{2}$, or $9 \%$ of China's net decrease in wetlands. In particular, palustrine wetlands, lacustrine wetlands and coastal wetlands are decreasing, while riverine wetlands and artificial wetlands are increasing (Table 9).

Nearly half of the net change in national wetland reserves occurred in 1978-1990. This was probably due to the enclosure of wetlands for cultivation and water conservation, as communities endeavored to solve livelihood problems.

Table 9 Net change in national wetland area $\left(\mathrm{km}^{2}\right)$

\begin{tabular}{|c|c|c|c|c|c|c|}
\hline Period & Subtotal & Coastal wetlands & Riverine wetlands & Lacustrine wetlands & Palustrine wetlands & Artificial wetlands \\
\hline 1978-1990 & -3996.69 & -514.77 & 387.01 & -744.65 & -2031.90 & 609.06 \\
\hline 1990-2000 & -2161.84 & -277.52 & 1474.39 & -216.92 & -3068.35 & 527.27 \\
\hline 2000-2008 & -1993.94 & -226.20 & 713.20 & -674.15 & -586.08 & 215.71 \\
\hline Total & -8152.47 & -1018.49 & 2574.60 & -1635.72 & -5686.33 & 1352.04 \\
\hline
\end{tabular}


Over the last 30 years, palustrine wetlands declined by as much as $5686.33 \mathrm{~km}^{2}$, with the maximum reduction in 1990 2000 , although this was effectively controlled in 2000-2008. The rate of reduction of lacustrine wetlands was about $1 / 3$ of the decrease of palustrine wetlands, with the slowest rate of reduction in 1990-2000, although this accelerated in 2000-2008. Coastal wetland reduced by approximately $1 / 5$ of reduction of palustrine wetland, with a marked reduction in 1978-1990, although this was relieved in 2000-2008. Riverine wetland increased $2574.60 \mathrm{~km}^{2}$, in 1978-1990 it increased least, in 1990-2000 it increased the most, and in 2000-2008 it increased moderately. Artificial wetland increased the least; at approximately half the rate of riverine wetland, although this increased in 1978-1990 and 19902000, and diminished in 2000-2008.

Compared with the changes in China's wetlands, the similar changes in protected wetlands show a declining trend in natural wetlands and an increasing trend in artificial wetlands. The decrease in natural wetlands far exceeds the increase in artificial wetlands; the former has been partly transformed into the latter, and partly into non-wetland. Another similarity is that wetlands have all suffered from changes in wetland types and large-scale degradation. In particular, the important ecological functions of biodiversity protection and ecological security disappear with the loss of natural wetlands.

In China's coastal wetlands, the net change in national wetland reserves reaches $20 \%$ far higher than the national average of $8 \%$. This is because coastal wetland reserves are often located in developed areas with heavy population pressure, where land use often changes as a result of government policy.

The riverine wetland in national wetland reserves has increased by $2574.60 \mathrm{~km}^{2}$, indicating that national riverine wetland reserves are in good condition. Riverine wetlands are essential to wetland reserves and the basin river system, and are the final defense in ensuring the ecological security of wetlands.

\subsection{Evaluation of protection}

\subsubsection{Protection effects}

The area $(79 \%)$ of poor reserves is far higher than the number $(48 \%)$ of poor reserves, and both are higher than the areas or numbers of excellent and moderate reserves. Poor reserves thus occupy the leading status (Table 10).

Palustrine reserves are the main type of poor reserves; the numbers of poor lacustrine, marine/coast, and wildlife reserves are only $2 \%, 3 \%$ and $16 \%$ respectively. Lacustrine reserves form the majority of the excellent reserves.

\subsubsection{Analysis of different types of reserves}

Of the 20 marine/coast reserves, 11 are poor with a total area of $7.06 \times 10^{3} \mathrm{~km}^{2}$, and an area ratio of $70 \%$. Number and area ratios of excellent and moderate reserves are both
$15 \%$. Three reserves in Hainan were not evaluated due to the lack of data. We consider that marine/coast reserves are generally in poor condition. In the three riverine reserves, Henan Dan River is excellent with an area of $640.20 \mathrm{~km}^{2}$, Henan Yellow River is moderate with an area of 680.00 $\mathrm{km}^{2}$, and Xinxiang Yellow River is poor with an area of $227.80 \mathrm{~km}^{2}$. Of the 16 lacustrine reserves, 7 are poor and 6 are excellent, with area ratios of $12 \%$ and $68 \%$ respectively. Of the 28 palustrine reserves, 13 are poor with a large total area of $1.65 \times 10^{5} \mathrm{~km}^{2}$, and $88 \%$ of the area. This shows that the protection for palustrine reserves is poor as a whole. Of the 24 wildlife reserves, 12 are poor with a total area of $3.33 \times 10^{4} \mathrm{~km}^{2}$, and $91 \%$ of the area. This means that wildlife reserves are also generally poor. We can thus conclude that palustrine, wildlife, and marine/coast reserves are generally in poor condition, and lacustrine and riverine reserves are, by comparison, in better condition.

\subsubsection{Analysis of different evaluation indices}

Table 11 shows considerable differences between the protection effect evalution indices, and thus supports the reliability of evaluation results.

Of the 44 poor reserves, 21 are poor in protection value, 24 are poor in wetland changes evaluation, 9 are poor in proliferation, and 5 are poor in functional zoning adjustment. Of the 16 moderate reserves, 12 have protection values lower than 71. The wetlands changes in Guangxi Shankou, the Inner Mongolia Ordos and Qinghai Lake reserves were slightly lower than the threshold of $10 \%$. In addition, Henan Yellow River, Yangtze River Fish and Yalu River Estuary were places in which functional zoning adjustment were undertaken; the former two staying unchanged in area, while the area of the latter declined by $7 \%$. The 19 excellent reserves had high evaluation results for both protection value and proliferation, without short-sighted functional zoning adjustment causing protection to be replaced by development.

The moderate reserves are special and have great potential for protection. The wetland areas in these reserves often show an increase, and are even higher than that in the excellent reserves, however they often have relatively small areas and low biodiversity, as well as functional zoning adjustment for economic development.

Of the poor reserves, the largest is the Three Rivers Source with an area of $1.52 \times 10^{5} \mathrm{~km}^{2}$, and the smallest is Guangdong Futian with $10 \mathrm{~km}^{2}$. Of the moderate reserves, the largest is Qinghai Lake with approximately $5.00 \times$ $10^{3} \mathrm{~km}^{2}$, and the smallest is Hubei Shishou with $20 \mathrm{~km}^{2}$. Of the excellent reserves, the largest reserve is Dalai Lake with $7.4 \times 10^{3} \mathrm{~km}^{2}$, and the smallest is Hainan Dongzhaigang with $30 \mathrm{~km}^{2}$.

Of the excellent reserves, the Heilongjiang Xingkai Lake has the greatest protection value of 84 , and the Heilongjiang Naoli River has the lowest protection value of 71. Of the moderate reserves, the Yangtze River Fish has the greatest 
Table 10 Number and area of national wetland reserves under different types of protection

\begin{tabular}{|c|c|c|c|c|c|c|}
\hline Protection effect & Type & Number & Ratio (\%) & Area $\left(\mathrm{km}^{2}\right)$ & Ratio (\%) & Examples of reserves \\
\hline \multirow{6}{*}{ Excellent } & 1 & 3 & 16 & 1516.20 & 4 & Guangdong Zhanjiang Mangrove, Hainan Dongzhaigang \\
\hline & 2 & 1 & 5 & 640.20 & 2 & Henan Dan River \\
\hline & 3 & 6 & 32 & 19281.00 & 48 & Heilongjiang Xingkai Lake, Eastern Dongting Lake \\
\hline & 4 & 8 & 42 & 18000.60 & 45 & Heilongjiang Zalong, Jilin Momoge \\
\hline & 5 & 1 & 5 & 780 & 2 & Jiangsu Dafeng \\
\hline & 6 & 19 & 21 & 40218.00 & 15 & \\
\hline \multirow{6}{*}{ Moderate } & 1 & 3 & 19 & 1291.10 & 11 & Guangxi Shankou, Zhejiang Nanji Islands \\
\hline & 2 & 1 & 6 & 680.00 & 6 & Henan Yellow River \\
\hline & 3 & 2 & 13 & 5285.40 & 44 & Anhui Shengin Lake, Qinghai Lake \\
\hline & 4 & 5 & 31 & 3559.60 & 29 & Heilongjiang Three Rivers, Guizhou Caohai, Jilin Hani \\
\hline & 5 & 5 & 31 & 1289.90 & 11 & Inner Mongolia Ordos Larus relictus \\
\hline & 6 & 16 & 18 & 12106.00 & 5 & \\
\hline \multirow{6}{*}{ Poor } & 1 & 11 & 25 & 7064.00 & 3 & Jiangsu Yancheng, Shandong Yellow River Delta \\
\hline & 2 & 1 & 2 & 227.80 & 0.1 & Henan Xinxiang Yellow River \\
\hline & 3 & 7 & 16 & 3385.38 & 2 & $\begin{array}{l}\text { Jiangxi Nanji, Jilin Chagan Lake, } \\
\text { Inner Mongolia Dalainur Lake }\end{array}$ \\
\hline & 4 & 13 & 30 & 164723.10 & 79 & Qinghai Three Rivers Source, Sichuan Ruo'er'gai \\
\hline & 5 & 12 & 27 & 33335.30 & 16 & Yunnan Dashanbao \\
\hline & 6 & 44 & 48 & 208735.58 & 79 & \\
\hline \multirow{7}{*}{ Not assessed ${ }^{\text {a) }}$} & 1 & 3 & 25 & 154.00 & 6 & Hainan Dazhou Island, Hainan Shanya Coral Reef \\
\hline & 2 & 0 & 0 & 0 & 0 & \\
\hline & 3 & 1 & 8 & 220.00 & 8 & Hubei Longgan Lake \\
\hline & 4 & 2 & 17 & 1305.60 & 48 & Heilongjiang Hong River, Jilin Xianghai \\
\hline & 5 & 6 & 50 & 1036.00 & 38 & Guangdong Huidong, Shandong Changdao \\
\hline & 6 & 12 & 13 & 2715.60 & 1 & \\
\hline & Total & 91 & 100 & 263775.18 & 100 & \\
\hline
\end{tabular}

a) Because of data shortage, 12 reserves were without evaluation. 1, Marine/coast reserves; 2, riverine reserves; 3, lacustrine reserves; 4 , palustrine reserves; 5 , wildlife reserves; 6 , subtotal.

Table 11 Comparative analysis of different evaluation indices of China's national wetland reserves

\begin{tabular}{lrccc}
\hline & & \multicolumn{2}{c}{ Indices of protection effect evaluation } \\
\cline { 3 - 5 } Protection effect & Area $\left(\mathrm{km}^{2}\right)$ & $\begin{array}{c}\text { Index of protection } \\
\text { value }\end{array}$ & $\begin{array}{c}\text { Index of wetland } \\
\text { change evaluation }\end{array}$ & $\begin{array}{c}\text { Index of proliferation } \\
\text { evaluation }\end{array}$ \\
\hline Excellent & 2116.74 & 76 & $+101 \%$ & $+172 \%$ \\
Medium & 756.70 & 71 & $+167 \%$ & $+14 \%$ \\
Poor & 4743.99 & 69 & $-99 \%$ & $+2 \%$ \\
\hline
\end{tabular}

protection value of 89 , and the Inner Mongolia Erdos has the lowest protection value of 65 . Of the poor reserves, the Three Rivers Source has the greatest protection value of 93, and the Guangxi Beilun Estuary has the lowest protection value of 50 .

Of the excellent reserves, the Gansu Dunhuang Xihu shows the greatest acceleration in wetland change rate with a two-fold increase, and Inner Mongolia Ke'er'qin shows the smallest acceleration in wetland change rate with a quarter-fold increase. Of the moderate reserves, the Henan Yellow River shows the greatest acceleration in wetland change rate with a nine-fold increase, and Guangxi Shankou 
shows the smallest acceleration of wetland change rate with a 9\% decrease. Of the poor reserves, Dalian Phoca largha also shows a nine-fold increase, and Gansu Gahai-zecha shows a seven-fold decrease.

\subsubsection{Analysis of different regions}

(i) At the regional level. The poor reserves are widely distributed throughout each wetland region, but mainly in the wetland regions of the Yangtze River, the Coast, the Three Rivers Source, and Southwest China. In particular, the poor reserves are found in the wetland subregions of the Lower Reaches of the Jinsha River, the Chaochuwan Reaches of the Yangtze River, Poyang Lake, Hebei, and the Tianjin Coast, the North Coast of Shandong Peninsula, the Jiangsu Coast, the South Coast of Fujian, Lazi to the Paixiang Reaches of the Yarlung Zangbo River, and the Lower Reaches of the Lancang River Bijiang Estuary. In addition, they are scattered through the wetland subregions of the Tianshan Mountains North Foothills, the Gansu Corridor, the Lower Reaches of the Nen River, and the Tongnan and Chongming Island Reaches of the Yangtze River (Figure 1).

At present, there are no moderate reserves in the wetland regions of the Three Rivers Source and Southwest China. They occur scattered in various subregions, such as the Yalu River, Sanmenxia to the Huayuankou Reaches of the Yellow River, Coast of Southern Zhejiang, Qinghai Lake, Yibing to Yichang Reaches of the Yangtze River, the Chaochuwan Reaches of the Yangtze River, and the lower reaches of the Yangtze River.

The excellent reserves are mainly distributed in the wetland region of the Songhua River, especially in the subregions of the Nen River, the Wusuli River, the Mudan River and the E'er'guna River. There are also excellent reserves in the wetland subregion of the Main Liao River, for example, the Shuangtai Estuary reserve in Liaoning. The excellent reserves in the wetland region of the Yangtze River exist in the subregions of the Yalong River and Han River. There are no excellent reserves in the wetlands of the Three Rivers Source or Southwest China.

Attention should be focused on those subregions without national wetland reserves, because there are possibly protection gaps here. These subregions mainly include the Suifen River and the Tumen River in the wetland regions of the Songhua River; Mintuo River, Wu River and Tai Lake in the wetland region of the Yangtze River; South and North of the Pan River, Hongliu River, Yu River, West River, North River, East River, Zhu River Delta; Han River and Eastern Guangdong in the wetland region of the Zhu River; Hekou Town to Dragon Gate of the Yellow River, Upstream of Huai River, Mushusi River, North Hai River, Tuhaimajia River, Luan River and the Eastern Hebei Coast, Eastern Liao River, Western Liao River, and Huntai River in the wetland region of Huanghuaihailiao; Chaidamu Basin, Tuha basin, Altai Mountains South Foothills, the inland river of
Central and Western Asia, Gurban Tongut Desert, the source of the Tarim River, Kunlun Mountains North Foothills, the MainTarim River and Tarim Basin desert in the wetland region of Northwest China; the Red River, Nu River and Irawaddy River, Southern Tibet River and Western Tibet River in the wetland region of Southwest China; and the Qiantang River, Eastern Zhejiang River, Sorthern Zhejiang River, Eastern Fujiang River, and Min River in the wetland region of Southeast China.

In addition, we should pay attention to positive intervention measures. There is a common characteristic of the wetland subregions of the Western Guangdong Coast and the Wusuli River. Both have excellent, moderate, and poor reserves, such as the Guangdong Zhanjiang mangroves, the Heilongjiang Xingkai Lake, and the Naoli River. There are excellent reserves in these two wetland subregions even though populations are dense, resulting in strong pressure on the ecological conditions. This is because of positive intervention measures taken in these areas, as previously discussed.

(ii) At the provincial level. There are poor reserves in each province except for Guizhou, Hainan and Zhejiang. The excellent reserves are mainly distributed in Heilongiiang, Jilin, Jiangsu and Inner Mongolia; each of these provinces has two excellent reserves. These provinces set an example to those provinces without excellent reserves, such as Anhui, Fujian, Guangxi, Guizhou, Hebei, Hubei, Jiangxi, Ningxia, Qinghai, Shandong, Shanghai, Tianjin, Yunnan and Zhejiang. The reserves in Hunan, Gansu, Heilongjiang, Inner Mongolia, Sichuan, Xinjiang and Henan are in good condition, and the number ratios of the excellent reserves in these provinces are all higher than 50\%. The reserves in Fujian, Shanxi, Hebei, Jiangxi, Ningxia, Tianjin, Tibet and Yunnan are all in poor condition. The reserves in Qinghai, Liaoning, Shandong, Anhui, Jiangsu, Hubei and Shanghai are partly in poor condition, and the number ratios of the poor reserves in these provinces are also higher than $50 \%$.

\subsection{Analysis of ecological pressure}

2.4.1 Analysis of reserves under different ecological pressures

Of 91 reserves, 52 are primitive. The area $(88 \%)$ of primitive reserves is far higher than the number $(57 \%)$ of primitive reserves, and both are higher than the areas or numbers of others reserves. This shows that the primitiveness of an ecosystem is an important criterion for protection by the Chinese government. But there remain some with high security pressure, even reaching the red level of warning, and this should be taken seriously (Table 12).

Of the 52 primitive reserves, palustrine reserves are the majority; the area (77\%) of palustrine reserves is far higher than the number $(35 \%)$ of palustrine reserves. Wildlife reserves follow, with ratios of $29 \%$ and $13 \%$ respectively. Marine/coast reserves, riverine reserves and lacustrine reserves 


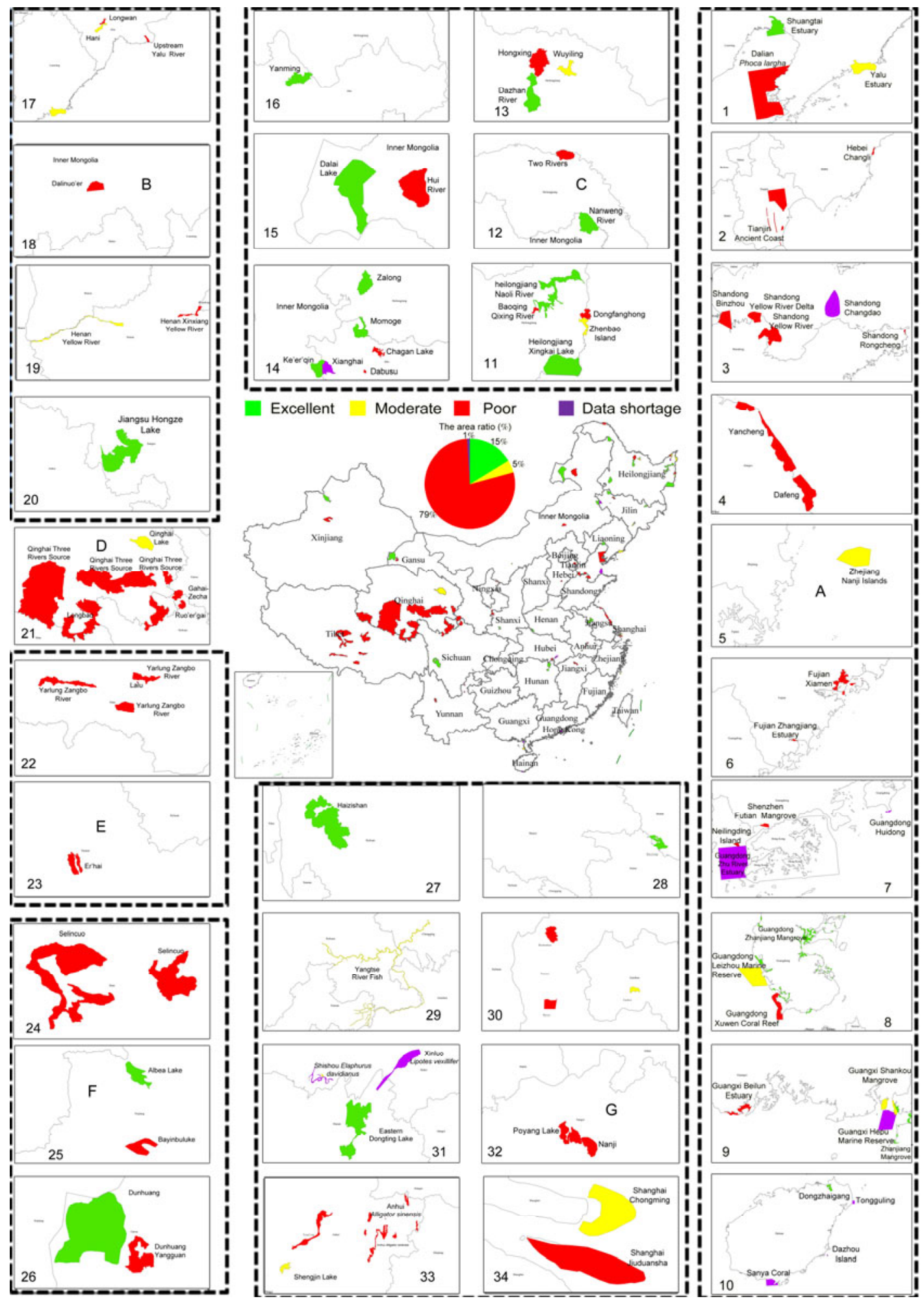

Figure 1 Protection effects for China's national wetland reserves. Wetlands regions: A, Coast; B, HuangHuaiHaiLiao; C, Songhua River; D, Three Rivers Source; E, Southwest China; F, Northwest China; G, the Yangtze River. Wetland subregions: 1, Coast of Western Liaodong Peninsula; 2, Coast of Hebei and Tianjin; 3, Coast of Northern Shandong Peninsula; 4, Jiangsu Coast; 5, Coast of Southern Zhejiang; 6, Coast of Southern Fujian; 7, Coast of Eastern Guangdong; 8, Coast of Western Guangdong; 9, Guangxi Coast; 10, Hainan Coast and South China Sea Islands; 11, Wusuli River; 12, Upstream of Heilong River; 13, Upstream of Nen River; 14, Middle and lower reaches of Nen River; 15, E'er'guna River; 16, Mudan River; 17, Yalu River; 18, Southern Hai River; 19, Yellow River; 20, Middle reaches of Huai River; 21, Three Rivers Source; 22, Lazi to Paixiang of Yalu Tsangpo River; 23, Downstream of Lancang River; 24, Qiangtang Plateau; 25, Tianshan Mountains North Foothills; 26, Gansu Corridor; 27, Yalong River; 28, Han River; 29, Yibing to Yichang of Yangtze River; 30, Downstream of Jinsha River; 31, Dongting Lake and Yichang to Lake Outlet in Yangtze River; 32, Poyang Lake; 33, Chaochuwan reaches of Yangtze River; 34, Tongnan and Chongming Island in Yangtze River. 
Table 12 Number and area ratios for China's national wetland reserves under different pressures on the ecology

\begin{tabular}{|c|c|c|c|c|c|c|}
\hline Rank & Type & Number & Ratio (\%) & Area $\left(\mathrm{km}^{2}\right)$ & Ratio (\%) & Examples of reserves \\
\hline \multirow{6}{*}{ Primitive } & 1 & 9 & 17 & 1865.80 & 1 & Zhejiang Nanji Islands, Hainan Tongguling \\
\hline & 2 & - & - & - & - & - \\
\hline & 3 & 10 & 19 & 22316.20 & 10 & Sichuan Haizishan, Qinghai Lake \\
\hline & 4 & 18 & 35 & 178391.00 & 77 & Dunhuang Xihu, Qinghai Three Rivers Source \\
\hline & 5 & 15 & 29 & 30269.00 & 13 & Guangxi Beilun Estuary, Tibet Selincuo \\
\hline & 6 & 52 & 57 & 232842.10 & 88 & - \\
\hline \multirow{6}{*}{ Yellow } & 1 & 7 & 29 & 5810.20 & 28 & Jiangsu Yancheng, Shandong Yellow River Delta \\
\hline & 2 & 1 & 4 & 227.80 & 1 & Henan Xinxiang Yellow River \\
\hline & 3 & 2 & 8 & 3021.90 & 15 & Heilongjiang Xingkai Lake, Yunnan Er'hai \\
\hline & 4 & 8 & 33 & 6151.90 & 30 & Zalong, Guizhou Caohai, Tibet Lalu \\
\hline & 5 & 6 & 25 & 5519.80 & 27 & Yunnan Huize, Shandong Rongcheng \\
\hline & 6 & 24 & 26 & 20731.50 & 8 & - \\
\hline \multirow{6}{*}{ Orange } & 1 & 3 & 25 & 1359.20 & 21 & Guangdong Futian, Fujian Xiamen \\
\hline & 2 & 2 & 17 & 1320.30 & 20 & Henan Yellow River, Henan Dan River \\
\hline & 3 & 2 & 25 & 713.78 & 11 & Hebei Hengshui Lake, Jiangsu Hongze Lake \\
\hline & 4 & 2 & 17 & 3046.00 & 46 & Jilin Momoge, Heilongjiang Naoli River \\
\hline & 5 & 1 & 17 & 135 & 2 & Xinluo Lipotes vexillifer \\
\hline & 6 & 10 & 12 & 6574.28 & 2 & - \\
\hline \multirow{6}{*}{ Red } & 1 & 1 & 25 & 990.00 & 29 & Tianjin Ancient Coast \\
\hline & 2 & - & & - & & - \\
\hline & 3 & 1 & 25 & 1900.00 & 56 & Eastern Dongting Lake \\
\hline & 4 & - & & & & - \\
\hline & 5 & 2 & 50 & 517.40 & 15 & Anhui Alligator sinensis, Yangtze River Fish \\
\hline & 6 & 4 & 4 & 3407.40 & 1 & - \\
\hline \multirow[t]{2}{*}{ Not assessed } & 3 & 1 & 1 & 220.00 & 0.1 & Hubei Longgan Lake \\
\hline & Total & 91 & 100 & & 100 & - \\
\hline
\end{tabular}

a) 1, Marine/coast reserves; 2 , riverine reserves; 3 , lacustrine reserves; 4, palustrine reserves; 5 , wildlife reserves; 6 , subtotal.

are few; this highlights the over-exploitation of beaches for urban expansion and fish farm development. Of the 24 yellow early warning reserves, palustrine reserves, marine/ coast reserves and wildlife reserves are in the majority, while lacustrine reserves and riverine reserves are in the minority. Of the 10 orange early warning reserves, marine/coast reserves, palustrine reserves and riverine reserves have the greatest area. Of the 4 red early warning reserves, there are 2 wildlife reserves, 1 lacustrine reserve, 1 coastal reserve, and no riverine reserve or palustrine reserve. The area ratios of lacustrine and coastal reserves are $56 \%$ and $29 \%$, higher than the area ratio $(15 \%)$ of wildlife reserves.

2.4.2 Analysis of the ecological pressure in different kinds of reserves

Of the 20 marine/coast reserves, 7 received yellow warning, 3 received orange warning, and 1 received red warning. These early warning reserves have area ratios of $58 \%, 13 \%$ and $10 \%$ respectively. In total, eco-insecure reserves are in the majority, and $70 \%$ of these are yellow reserves.

Of the 3 riverine reserves, Henan Yellow River, Dan River and Xingxiang Yellow River are all in Henan Province, the first two received orange warning with a total area of $1.32 \times 10^{3} \mathrm{~km}^{2}$, accounting for $85 \%$ of the total area of riverine reserves, and the third received yellow warning. In addition, there are no red warning or primitive reserves.

Of the 16 lacustrine reserves, 10 are primitive with an area of $2.23 \times 10^{4} \mathrm{~km}^{2}$ and an area ratio as high as $79 \%$. There are 2 receiving yellow warning, 2 receiving orange warning, 1 receiving red warning and 1 without evaluation, with area ratios of $11 \%, 3 \%, 7 \%$ and $0.1 \%$, respectively. In general, $70 \%$ of the lacustrine reserves are primitive.

Of the 28 palustrine reserves, 18 are primitive with a total area of $1.78 \times 10^{5} \mathrm{~km}^{2}$ and an area ratio of $95 \%, 8$ received yellow warning, 2 received orange warning, and there is no red warning reserve. Thus, $95 \%$ of the palustrine reserves are primitive.

Of the 24 wildlife reserves, 15 are primitive with a total 
area of $3.03 \times 10^{4} \mathrm{~km}^{2}, 6$ received yellow warning, 1 orange, and 2 red, with area ratios of $83 \%, 15 \%, 0.4 \%$ and $1 \%$ respectively. Thus, the most wildlife reserves are primitive.

In summary, more than $70 \%$ of palustrine, lacustrine and wildlife reserves are primitive, more than $70 \%$ of marine/ coast reserves received yellow warning, and all the riverine reserves are eco-insecure.

2.4.3 Analysis of pressure on the ecological conditions using different indices

We considered population density, cropland, and urban and rural residential land to be the most essential stress factors (Table 13 for details).

Primitive reserves can be characterized by having grassland and forest as the major types of land uses, with few cropland, urban and rural residential land. There are secondary roads and the population density is low, with only a few villages. The productive lifestyles of communities are based on tidal flats, forests and grassland. In the short term, these reserves are very natural with little human disturbance.

Yellow warning reserves usually have higher population densities, and the land is mostly cultivated and grassland, with forestor urban and rural residential land as auxiliary types of land uses. Roads are mainly secondary highways, with major highways as auxiliary uses. 1/3 of the yellow reserves include towns, and $1 / 2$ of them include residential land sites. The productive lifestyles of communities are mainly based on agroforestry, supplemented by fisheries and forestry.

Orange warning reserves are usually located in the suburbs of large urban areas, where the population density is extremely high and there are well-developed economic and transportation links. The land is primarily cropland. Roads are primarily major highways and secondary highways with cart tracks and lanes as auxiliary transportation pathways. More than half of the orange warning reserves are in towns, and almost of them are on residential land.

Red warning reserves usually have the highest population densities: some are as high as 412 people per $\mathrm{km}^{2}$. They have the most cultivated land: as much as $46 \%$. Over-development places great pressure on these red reserves, and can result in conflicts between the needs of communities and the needs of reserves.

\subsubsection{Analysis of ecological pressure in different regions}

Figure 2 shows that the primitive reserves are mainly distributed in the northwest and northeast of China, including Qinghai, Tibet, Xinjiang, Inner Mongolia, Yunnan, Guizhou, Gansu, Heilongjiang, Jilin and Liaoning. In addition, there are a few primitive reserves on the coast of Eastern China, such as Zhejiang Nanji Islands, Guangdong Zhu River Estuary, Guangdong Huidong and Dalian Phoca largha; and in Jiangxi and Anhui Provinces, such as Nanji wetland and Shengjin Lake.

These primitive reserves are mainly distributed in the wetland regions of the Three Rivers Source, Qiangtang Plateau, Gansu Corridor, Inner Mongolia, Qinghai Lake, and the Tianshan Mountains North foothills. In the wetland region of the Songhua River, they are mainly distributed in the sources of secondary basins, such as the sources of the Nen River, Heilong River, Songhua River, Second Songhua River and Yalu River; however, there are still some in the middle and lower reaches of some wetland subregions. In the wetland region of the Coast, they are mainly distributed in such wetland subregions as the coast of Western Liaodong Peninsula, the coast of Western Guangdong, the coast of Guangxi, Hainan, the South China Sea Islands, the coast of Southern Fujian, the Yangtze Estuary and the coast of Zhejiang.

The eco-insecure reserves are mainly distributed in Eastern and Central China, although some are in Northeast and Southwest China. There are no eco-insecure reserves in Northwest China. The red reserves are mainly distributed in the wetland region of the Yangtze River (the Yangtze River Fish, Anhui Yangtze Alligator sinensis and Eastern Dongting Lake).

Of the 10 orange warning reserves, 2 are in the wetland region of the Yangtze River (Henan Dan River and Xinluo Lipotes vexillifer), 4 are in the wetland region of the Huanghuaihailiao River Basins (Henan Yellow River, Jiangsu Hongze Lake, Hebei Hengshui Lake and Yalu Estuary of Liaoning), 2 are in the wetland region of Songhua River (Momoge and Naoli River), and 2 are in the wetland region of the Coast (Shenzhen Futian and Fujian Xiamen).

The 24 yellow warning reserves are widely distributed throughout each wetland region, except for the two wetland regions of Northwest China and the Three Rivers Source.

Table 13 The most essential stress factors for China's national wetland reserves

\begin{tabular}{|c|c|c|c|c|c|}
\hline \multirow{2}{*}{ Rank } & \multicolumn{4}{|c|}{ Ratios (\%) } & \multirow{2}{*}{$\begin{array}{l}\text { Population density } \\
\text { (people } \mathrm{km}^{-2} \text { ) }\end{array}$} \\
\hline & Urban and rural resident land & Cropland & Forestry land & Grassland & \\
\hline Red reserves & 4 & 46 & 23 & 4 & 412 \\
\hline Orange reserves & 9 & 35 & 8 & 4 & 326 \\
\hline Yellow reserves & 5 & 21 & 12 & 20 & 147 \\
\hline
\end{tabular}



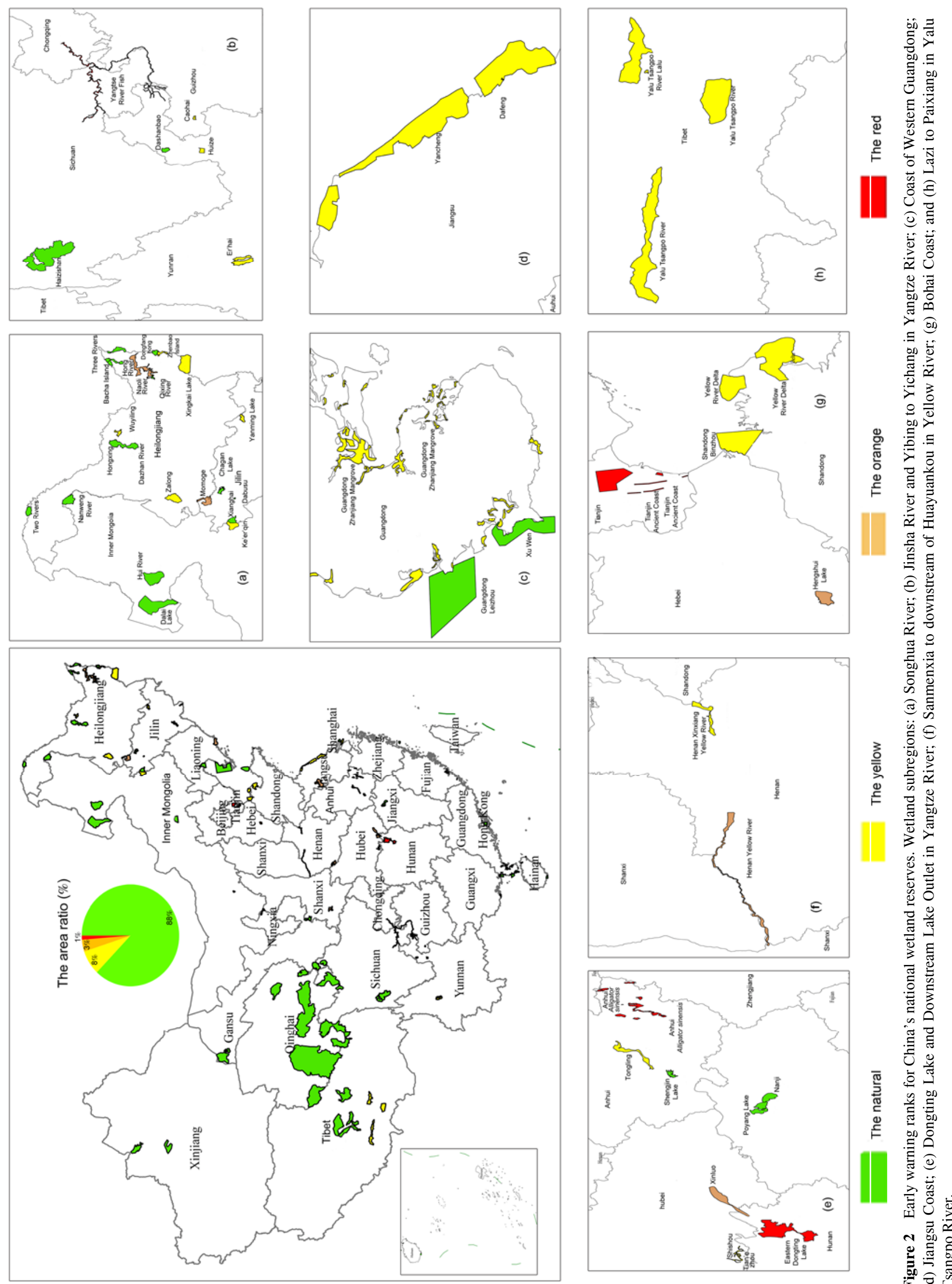

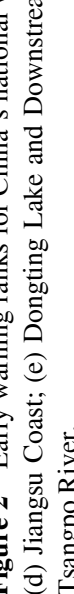


The wetland regions of the Songhua River and the Coast have the most yellow warning reserves, with the wetland regions of the Yangtze River, Huanghuaihailiao and Southwest China. Six are in the wetland region of the Songhua River, 6 are in the wetland region of the Coast (Guangdong Zhanjiang, Jiangsu Yancheng, Guangxi Shankou, Shanghai Jiuduansha, Shandong Rongcheng and Hebei Changli), 5 are in the wetland region of the Yangtze River (Yunnan Huize, Guizhou Caohai, Hubei Tian'e'zhou, Hubei Shishou and AnhuiTongling), 4 are in the wetland region of Huanghuaihailiao (Ningxia Haba Lake, Xinxiang Yellow River, Shandong Binzhou and Yellow River Delta), and 3 are in the wetland region of Southwest China (Tibet Lalu, Yalu Tsangpo River and Yunnan Er'hai).

The Yangtze River and China's lakes are of global significance; these regions have been determined by the World Wide Fund For Nature (WWF) $[33,34]$ as essential wetland biodiversity areas in China [26,34]. The wetland region of the Yangtze River is an important base for Chinese grain, cotton and kapok, oil and aquatic products, and its agricultural development history is outstanding. Wetland protection is facing tremendous pressure from fast economic development and agricultural exploitation, leading to reduction in natural wetlands $[35,36]$. This explains why there are so many eco-insecure reserves of all kinds in this region.

Most provinces have primitive reserves except for Guizhou, Hebei, Henan, Hunan, Hubei, Ningxia and Beijing. These primitive reserves are concentrated in Heilongjiang and Jinlin (9 and 6, respectively). Guangdong, Hainan and Inner Mongolia both have 4 primitive reserves, while Qinghai, Sichuan, Gansu, Liaoning, Guangxi, Jiangxi and Xinjiang have 2 or 3 primitive reserves.

\subsection{Analysis of results and suggestions on protection}

We have quantitatively analyzed the contributions to reserves of natural and anthropogenic factors from the point of eco-security, and have illustrated the main protection effects. Finally, we make some proposals for protection following our evaluation of protection effects and pressures on wetland ecology.

\subsubsection{The effect of natural factors on protection}

The primitive reserves in the Qinghai-Tibetan Plateau, for example, have mostly poor protection status but with few human threats. However, with global warming, glaciers and permafrost melting, average annual temperature rising, precipitation decreasing, surface evaporation increasing, and lack of water in local areas, the areas of wetlands such as those in the Three Rivers Source have reduced sharply. These reserves need extensive management because of their large areas, but have insufficient management. It is difficult to carry out effective protection measures such as species propagation and habitat transformation, and these problems are especially severe for the Grus nigricollis-oriented re- serves such as Selincuo, Rongbao, Huize and Dashanbao.

Some excellent reserves have high naturalness with abundant surface runoff. Haizishan, for example, has 1145 alpine lakes with a unique lake density in China, and is the source of the Jinsha and Yalong Rivers [37]. It is also the most typical, best preserved, and largest area of ancient glacial relief on the Qinghai-Tibetan Plateau, and has abundant biodiversity. In Gahai-zecha reserve, the peatland has seriously degenerated and has fewer vegetation types, lower vegetation coverage and is bare over some local areas, according to a survey in 2009 by Martin, an international peat expert [38]. Long-term water erosion from human activities has led to riverbeds and creeks being scoured gradually by more than $1 \mathrm{~m}$, with some places even reaching $1.8 \mathrm{~m}$, and the peatland has gradually degraded from lack of water [38]. Artificial drainage is the main reason for peatland degradation in the Ga'er'niang, Jiacang, and Bohai areas. Rising temperatures and precipitation decreases have also led to peatland degradation.

\subsubsection{The effects of human factors on protection}

(i) Human factors influencing poor reserves. Eco-insecure reserves or poor reserves are always located in suburban areas where there are intensive land use, well-developed road networks, and huge population pressure. In addition, the developing economy and expanding cities make dramatic demands for water. Damming, over-exploitation of groundwater, irrational use of water resources and inadequate water-saving measures, all disturb the water supply of reserves, accelerate degradation and loss of wetlands, and create pollution problems and threats for environmental water and reserve biodiversity. Moreover, the land of some reserves is not completely owned by the reserve authorities, and is often becoming the target of functional zoning adjustments for the purpose of "protection making way for development" under pressure from local government. This action in violation of "Regulations on Nature Reserves", sacrifices reserves, exacerbates wetland loss, biodiversity reduction and species extinction. Taking the reserves located in the lower-middle reaches of Yangtze River as examples, the main reasons for their decline are as follows.

Draining lakes for farmland has destroyed wetlands and accelerated the process of lakes becoming swamps. The areas of lakes are decreasing, and their regulatory and storage functions are gradually reducing [39]. Wetland reclamation and the establishment of water conservation facilities upstream have threatened reserve hydrologies, and changes in wetland water resources have seriously affected ecological conditions and wildlife [40]. Species propagation has been insufficient and restricted by environmental conditions [41]. The instability of water levels has created abnormal habitats for species; some important habitats have gradually disappeared as human activities have continued to erode reserves [42]. Functional zoning has been frequently readjusted (http://sts.mep.gov.cn/zrbhq/pxbz/index.htm, 2011).

(ii) Human factors influencing excellent reserves. Ex- 
cellent reserves that are ecologically insecure benefit from effective protection measures as follows:

(1) Implementing the project of reverting cropland to forests, grass and wetlands. The Naoli River and Xingkai Lake are the largest reserves in the Heilongjiang reclamation area, for example, and both belong to the wetland subregion of the Wusuli River. Initially these were the main components of the "Great Northern Wilderness". The reserve authorities have established and effectively implemented the protection of wetlands and biodiversity, as well as taking measures such as conversion from cropland to forest, grassland and wetland [43].

(2) Implementing effective management for wetland resources. Guangdong Zhanjiang reserve contains China's largest area of mangroves and largest number of mangrove species (24); there are $71.863 \mathrm{~km}^{2}$ mangroves in the reserve, a total of $33 \%$ of the mangroves in China [44]. The governments of China and Netherlands implemented programs of protection and management of mangroves as important natural coastal resources. Since 2001, the key to these programs has been mangrove restoration, protection, education and community co-management [45]. Then it was listed into "International Importance Wetland Catalogue" in 2002.

(3) Implementing water transfer at basin level. Albea Lake is the largest lagoon in Xinjiang, and human activities were the main reason for the rapid deterioration of this lake. However, after the establishment of a reserve, the local government implemented water transfer many times [46-47]. The lake has increased in size.

(4) Implementing proliferation of endangered species. The reason for the establishment of the Jiangsu Dafengreserve in Jiangsu was to achieve a return to nature and in-situ conservation through the provision of ex-situ conservation. Elaphurus davidianus is a wetland deer unique to China that became extinct in the wild during the late Qing Dynasty [48]. The reserve was established by introducing 39 E. davidianus from zoos in the UK, and building fences for domestication from August 14, 1986. Over the years, the deers' physiological behaviors including estrus, mating, calving, antler growth, molting and feeding have become understood by scientists, and an anaesthetic technique enabling control of diseases has been developed. By June 2008, under projects such as "Introduction to Expanded Group", "Behavior Remodeling" and "Release into the Wild", the total number had grown to 1317 , or $1 / 3$ of the world population. Some technical indicators such as the rate of annual growth, survival and annual increase have been the best in the world. The number in the wild is now 118; authentically achieving the target of reintroducing an extinct wild population and achieving natural reproduction. This epoch-making event was a tremendous success story for world conservation [48].

\subsubsection{Suggestions for protection}

(i) Suggestions for enhancing protection effects. Protec- tion effects and pressures on reserve ecology are determined by many factors. How to increase protection effects based on the present limited financial resources remains a challenge. We have prioritized the reserves based on our evaluations of protection effects and pressures on the ecology. Poor and ecologically insecure reserves, or moderate and orange warning reserves, or red warning reserves, were listed for prioritized implementation of appropriate protective measures. These have been determined by the protection effects, pressures on ecology, main protection objectives and the most essential stress factors (Table 14).

A long-term protection plan should be worked out for those reserves on the priority list, and more reasonable and effective protection measures should be undertaken to further consolidate and enhance protection effects, such as investigating the replenishment of biodiversity, intensive distribution areas and important habitats for endangered species. The reserves on the priority list should receive investment for enhancement of protection as soon as possible. The following measures for protection and management can be adopted:

Water purification, habitat building and artificial feeding (to attract species by enhancing their habitat) $[42,49]$, increasing biodiversity and enhancing the protection value of reserves. Increasing the area of wetland by water transfer implementation, and permanently maintaining the health and stability of wetland ecosystems. Expanding the number of endangered species breeding in the wild,and enhancing the proliferation level of reserves. Construction of biological corridors and intermediate areas by formation of a substantial network between reserves to ensure genetic exchange. Adjusting functional zoning with caution and enhancing the ratio of wetland area to core zones, to ensure security of wetland biodiversity and its habitat. Developing financial channels and guiding communities towards organic agriculture and eco-tourism. Renting or purchasing the right of land use to protect a wetland of significance during a special season. Carrying out the work of the System Conservation Program [50] by analyzing the main protection database, in terms of biodiversity, ecosystem characteristics, land use, population pressure and roading.

(ii) Suggestions for reducing pressure on ecology. The development of reserves faces stern challenges because there have already become conflict zones between human development and wetland protection. The big question is how we ensure eco-security, and thoroughly eliminate passive situations of poor protection efforts and excessive pressure on ecological conditions. Some suggestions on reducing pressure are proposed as follows:

(1) Implementing integrated basin management. The establishment of a wetland resource management committee at basin level is suggested, to build a foundation for the management of water resources, water quality monitoring and wetland biodiversity protection.

(2) Advancing wetland legislation positively. Laws such 
Table 14 Priority list for China's national wetland reserves

\begin{tabular}{|c|c|c|c|c|}
\hline Order & Protection effect & Ecological pressure & Name of reserve & Population density (people $\mathrm{km}^{-2}$ ) \\
\hline 1 & poor & red & Anhui Alligator sinensis & 261 \\
\hline 2 & poor & red & Tianjin Ancient Coast & 218 \\
\hline 3 & poor & orange & Fujian Xiamen & 910 \\
\hline 4 & poor & orange & Guangdong Futian & 764 \\
\hline 5 & poor & orange & Hebei Hengshui Lake & 380 \\
\hline 6 & poor & yellow & Anhui Tongling & 347 \\
\hline 7 & poor & yellow & Hebei Changli & 386 \\
\hline 8 & poor & yellow & Jiangsu Yancheng & 36 \\
\hline 9 & poor & yellow & Ningxia Haba Lake & 9 \\
\hline 10 & poor & yellow & Shandong Yellow River Delta & 34 \\
\hline 11 & poor & yellow & Shandong Rongcheng & 141 \\
\hline 12 & poor & yellow & Shandong Binzhou & 133 \\
\hline 13 & poor & yellow & Shanghai Jiuduansha & 86 \\
\hline 14 & poor & yellow & Henan Xinxiang Yellow River & 91 \\
\hline 15 & poor & yellow & Tibet Lalu & 404 \\
\hline 16 & poor & yellow & Tibet Yalu Tsangpo River & 17 \\
\hline 17 & poor & yellow & Yunnan Huize Grus nigricollis & 138 \\
\hline 18 & poor & yellow & Yunnan Er'hai & 55 \\
\hline 19 & excellent & red & Eastern Dongting Lake & 501 \\
\hline 20 & moderate & red & Yangtze River Fish & 668 \\
\hline 21 & moderate & orange & Henan Yellow River & 204 \\
\hline 22 & moderate & orange & Liaoning Yalu Estuary & 253 \\
\hline
\end{tabular}

as the "Wetland Protection Management Rule", the "Wetland Biodiversity Protection Rule", and the "Categorizing Principle of Wetland Reserves in China" should be drawn up as soon as possible. These laws are suggested to promulgate the regulation of wetland resources based on revising the existing laws around water, tidal flats, rivers, lakes, marshes, islands, wildlife and land use, and should be helpful for integrated basin management, wetland protection and economic development. Wetland protection should be a specified land use integrated into the state land use plan to ensure local eco-security. In addition, some important wetlands with high protection status should be purchased by the government to meet the needs of national eco-security system.

(3) Building natural conservation regions. Following the definition of a natural conservation region [51] and the distribution characteristics of China's national wetland reserves, 6 natural conservation regions are considered important. These are the Qinghai-Tibetan Plateau, the Three Rivers Plain, the Songnen Plain, the Plain of the middle and lower reaches of Yangtze River, the Bohai Coast, and the Nanhai Coast. Each natural conservation region has the purpose of protecting the same conservation objective, which includes several nature reserve groups convenient for management, and some reserves can be as the nodes for the network of reserves. To effectively protect the habitats of $G$. nigricollis on the Qinghai-Tibetan Plateau, for example, we can build nature reserve groups for $G$. nigricollis including four national wetland reserves such as Tibet Selincuo, the middle reaches of Yarlung Zangbo River in Tibet, Yunnan Dashanbao and Yunnan Huize. We can build nature reserve groups for mangroves on the Nanhai Coast, and nature reserve groups for Grus leucogeranus in the Plain of the middle and lower reaches of Yangtze River, and also nature reserve groups for the birds of Ciconiidae in the Plain of the Three Rivers and Songnen.

(4) Implementing remote sensing monitoring. A remote sensing monitoring plan for China's national wetland reserves should be implemented as soon as possible based on the dynamic situation of the main protection objective, protection effects, and pressures on the ecology. The plan should include remote sensing monitoring of land use, wetland boundaries, wetland transformation, and wetland biomass, as well as wireless transmission and long-distance remote control to and from the wetland ecosystem local station.

(5) Strengthening industry restructuring. An industry restructuring plan for China's national wetland reserves should also be drawn up as soon as possible. The present 
situation of industry structure, advantageous resources, and local economy should be first investigated, and then a plan for organic agriculture, eco-tourism, some related measures and preferential policies should be made out by the government.

\section{Uncertainty issues}

From the perspective of protection value evaluation, wetland change evaluation, wildlife population proliferationevaluation, and functional zoning adjustment evaluation, the protection effects of national wetland reserves have been preliminarily evaluated. Our paper aims to attract the attention of the state authorities primarily for reference.

First, a unified understanding has not been formed on many aspects of wetland reserves for evaluation of concepts, classification, and protection effects. At present, there is still no unified classification system or protection effect evaluation system for wetland reserves in China. All wetland reserves are completely managed and evaluated as strict nature reserve (Ia); conflicts exist between conservation and socio-economic development, and contradictions exist between different protection objectives with limited evaluation methods. It is necessary to strengthen research into the classification system and protection effect evaluation for wetland reserves.

Second, the database for protection value evaluation is based on science that spans 30 years; although it has been approved by experts it will contain some obsolete data. There are also delineating errors in maps of China's wetland derived from satellite data and in the distribution maps of China's national wetland reserves. Therefore, there are also some errors in our data about wetland change after spatial overlay. However, our findings are able to provide an important general overview of the protection effects of China's national wetland reserves.

Our results in relation to protection value evaluation are similar to those of Wang et al. [52] for Hongze Lake in Jiangsu Province. We gave a protection value of 77.7 , and Wang et al. [52] gave it a value of 80.2. Wang et al. [52] adopted 7 indices with high usage frequency: diversity, representativeness, rarity, naturalness, area suitability, stability, and human disturbance. Their grade division basis for evaluation indices is strongly subjective and worth further discussion. The grade division basis of evaluation indices that we used is relatively more scientific because it is based on the scientific reports of 182 wetland reserves.

Our results in relation to wetland change evaluation are quite similar to those of Deng et al. [53]. Our observations of the net reduction in palustrine wetland present astonishing consistency. The data sources and processing platforms are also consistent. A difference is that Deng et al. [53] used the landscape ecology taxonomic approaches of Xiao [54] and the landscape ecology software Fragstats 3.3 developed by the Forestry Labs of Oregon State University, USA.

At present, China has not established a remote sensing observation system for wetland reserves, and the overwhelming majority of wetland reserves are faced with various threats to different degrees. Internationally, attention has already been paid to research into marine protected areas [55], but in China research into marine reserves is lagging behind.

Third, the wetland change rate is a relative index and is closely linked to the area of reserves. However, the areas of some reserves have changed as a result of expansion, merger or adjustment.

Fourth, there is currently no standard for the biological corridor design of wetland reserves in China. Many wetland reserves are occupied by buildings and are influenced by human disturbance. The fragmentation of wildlife habitats further causes isolation of wildlife populations and accelerates their extinction rates. It is necessary to strengthen research into the protection effect evaluation of wildlife reserves, especially to consider the biological corridor problem.

Fifth, this article has not used management measures to evaluate systems of protection owing to data shortage; some measures possibly reduce ecological pressure and greatly enhance protection.

\section{Conclusions}

The purpose of our protection effect evaluation was to enhance the protection level of national wetland reserves, to suggest the government to perfect macroscopic management, and to suggest reserve authorities to strengthen management ability. The goal is to gradually form a safeguard system for wetland reserve protection to enhance the country's ecological security. This would have the reserves at its core and a government department in charge to guide and encourage widespread community co-management.

China's national wetland reserves are quite poor in total, especially palustrine and wildlife reserves. These poor reserves are widely distributed in the areas of the Qinghai-Tibetan Plain, Nen River, the middle and lower reaches of the Yangtze River, Yalu Tsangpo River, and Lancang River. The excellent reserves are mainly lacustrine reserves, and are distributed in the areas of the Xingkai Lake, Dalai Lake, Albea Lake, Haizishan, Eastern Dongting Lake, and Hongze Lake.

For the 91 national wetland reserves, the results of evaluating pressure on their ecological conditions are that the primitive reserves $>$ the yellow warning reserves $>$ the orange warning reserves $>$ the red warning reserves. Numbers are $52,24,11$, and 4 , respectively. $90 \%$ of palustrine reserves, and $70 \%$ of wildlife and lacustrine reserves are primitive reserves. The primitive reserves are mainly distributed in northwest and northeast of China. 70\% of marine/coast reserves are yellow warning reserves. There are 
1-3 orange warning reserves in each type. Anhui Alligator sinensis, Yangtze River Fish, Eastern Dongting Lake, and Tianjin Ancient Coast are red reserves. These ecologically insecure reserves are mainly distributed in the wetland region of the Yangtze River, the Coast wetland region, and in the middle and lower reaches of basins like the Nen River.

Research into the evaluation of protection effects of wetland reserves is still in its initial stages. It is difficult to estimate quantitatively the contribution of various stressors to protection effect evaluation, and there are some uncertainties. Our results are based on the obtainable data and are preliminary. As net primary productivity (NPP) can reflect the structure and function of wetlands, and point or non-point pollution affects the protection of reserves, future research should give these aspects some consideration.

We thank Professors Cui Guofa, Chen Jianwei, Yan Chenggao, and research fellow Cui Lijuan for their constructive comments on protection value evaluation. We thank the Nature Reserves Research Center of the State Forest Administration, the Nature Reserve Office in Guangdong, the Protection and Management Center in Fujiang for providing materials. We thank Xu Jiliang, Xing Shaohua, Gao Junqin, Lei Ting, Lou Dan, Li Xiaoyu, Li Yuqiang, Xuan Jing, Li Na, Zhou Shulin and Zeng Yajie for their assistance in document acquisition. We also thank Professors Arthur Cracknell and Pauline Lovell for correcting the English in an earlier draft of this paper. This work was supported by the National High Technology Research and Development Program of China (2009AA12200307) and the Key Projects in the National Science \& Technology Pillar Program (2008BADBOBO1)

1 Costanza R, d' Arge R, de Groot R, et al. The value of the world's ecosystem services and natural capital. Nature, 1997, 387: 253-260

2 Duarte C M, Middelburg J J, Caraco N. Major role of marine vegetation on the oceanic carbon cycle. Biogeoscience, 2005, 2: 1-8

3 Kremen C, Cameron A, Moilanen A, et al. Aligning conservation priorities across taxa in Madagascar with high-resolution planning tools. Science, 2008, 320: 222-226

4 Cao L, Fox A D. Birds and people both depend on China's wetlands. Nature, 2009, 460: 173

5 Valiela I, Fox S E. Ecology-Managing coastal wetlands. Science, 2008, 319: 290-291

6 Lv X G, Liu X H. Wetland research orogresses in China: Dedicated to the 50th anniversary of Northeast Institute of GeoCharty and Agroecology, CAS (in Chinese). Sci Geo Chart Sin, 2008, 28: 301-307

7 Cui L J, Bao D M, Xiao H. Calculation methods of wetland ecological water and case study (in Chinese). J Soil Water Conserv, 2005, 19: 147-151

8 Gong $\mathrm{P}$, Niu Z G, Cheng X. Chinese wetland change remote sensing between 1990 and 2000 year (in Chinese). Sci China Ser D Earth Sci, 2010, 40: 768-775

9 Cui G F. Special research fields and hot spots in science of nature reserves (in Chinese). J Beijing Forest Univ, 2004, 26: 102-105

10 Shi G F. The type and distribution of Chinese nature reserves (in Chinese). J Northwest Univ, 1987, 17(Suppl): 12-20

11 Xue D Y, Jiang M K. A study on categoring standard of nature reserves in China (in Chinese). China Environ Sci, 1994, (4): 246-251

12 The Editorial Board of Encyclopedia of Chinese Wetland. Encyclopedia of Chinese Wetland (in Chinese). Beijing: Beijing Science and Technology Publishing House, 2008

13 Zheng Y M. Studies on the protection value evaluation of wetland nature reserve and Gaps (in Chinese). Doctoral dissertation. Beijing: Graduate School of Beijing Forestry University, 2010. I, 45, 54, 125

14 Jiang M K, Wang Z, Qin W H. Effectiveness of national priority wildlife protection in nature reserves (in Chinese). J Ecol Rur Environ, 2006, 22: 35-38, VI

15 Tang X W. Pay attention to Chinese ecological security (in Chinese). Sci Technol Daily, 2002-3-15

16 Xue X Z, Lin T, Cao X H. Building coastal ecological safety indicator system (in Chinese). J Xiamen Univ (Nat Sci), 2004, 43 (Suppl): 179-183

17 Giri C, Ochieng E, Tieszen L L. Status and distribution of mangrove forests of the world using earth observation satellite data. Glob Ecol Biogeogr, 2011, 20: 154-159

18 Pattanaik C, Reddy C S, Prasad S N. Mapping, monitoring and conservation of Mahanandi wetland ecosystem, Orissa, India using remote sensing and GIS. Proc Natl Acad Sci India Sect B Biol Sci, 2008, 78: 81-89

19 Schleupner C. GIS-based estimation of wetland conservation potentials in Europe. Lect Notes Comp Sci, 2010, 6016: 193-209

20 Cui L J, Li W, Zhang M Y. Changes in landscape pattern of mangrove wetlands and their driving force in the Luoyang river estuary, Fujian Province (in Chinese). J Beijing Forest Univ, 2010, 32: 106-112

21 Niu Z G, Gong P, Cheng X. Chinese wetland remote sensing mapping and related geochartic feature analysis (in Chinese). Sci China Ser D Earth Sci, 2009, 39: 188-203

22 Niu Z G, Zhang H Y, Gong P. More protection for China's wetlands. Nature, 2011, 471: 305

23 Wu S X, Yuan H F. The Scientific Report of Dunhuang Xihu National Nature Reserve in Gansu Province (in Chinese). Beijing: China Forestry Press, 2010

24 Zheng Y M, Cui G F, Lei T, et al. Coupling relationship between the average coverage of wetland plant communities and soil salinity in Dunhuang Xihu Wetland of Gansu Province (in Chinese). Acta Ecol Sin, 2009, 29: 4665-4672

25 Zheng Y M, Cui G F, Lei T, et al. Community characteristics and population patterns of Tamarix ramosissima in Dunhuang Xihu of Gansu Province, northwestern China (in Chinese). J Beijing Forest Univ, 2010, 32: 34-44

26 Gao J Q, Zheng Y M, Zhang M X, et al. The GAP analysis of wetland conservation in Central Yangtze Ecoregion (in Chinese). Wetland Sci, 2011, 9: 42-46

27 Zheng Y W, Xue D Y, Zhang G S. Study on ecological evaluation criteria and standards for nature reserves in China (in Chinese). Rural Eco-environment, 1994, 10: 22-25

28 Yang J, Wang W Y. Application of analytic hierarchy process in ecological assessment on natural reserves (in Chinese). Indust Safety EnvironProtect, 2007, 33: 27-29

29 Hoffmann M, Taylor C H, Angulo A. The impact of conservation on the status of the World's vertebrates. Science, 2010, 330: 1503-1509

30 Wang S, Xie Y. China Species Red List, Vol 1. (in Chinese). Beijing: Higher Education Press, 2004

31 Li F. China Red Data Book of Endangered Animals (in Chinese). Beijing: Science Press, 1988

32 The Editorial Board of Chinese Bay. Chinese Bay (in Chinese). Beijing: Ocean Press, 1998

33 Myers N, Mittermeier R, Mittermeier C, et al. Biodiversity hotspots for conservation priorities. Nature, 2000, 403: 853-858

34 Li X W, Zheng Y, Zhao Z K. The Gap analysis of wetland conservation and its conservation netwoek building in central Yangtze Ecoregion (in Chinese). Acta Ecol Sin, 2007, 27: 4979-4989

35 Bao D M, Wang X L, Lv X G. Wetland protection basing on basin ecological management in the middle-lower reaches of the Yangtze river (in Chinese). Wetland Sci, 2006, 4: 96-100

36 Chen C Z, Lin Z S. Research progress of river and lake wetlands in the middle and lower reaches of Yangtze river based on domestic Chinese published papers from 1992 to 2008 (in Chinese). Wetland Sci, 2010, 8: 193-203

37 Li T, Hu Y Q, Zhang S R. Ecological environment evaluation on Haizishan natural reserve (in Chinese). Environ Sci Manag, 2011, 36: 172-175

38 Li H B, Li J Z. Technical assessment of restoration of degraded peat- 
lands in Gahai wetlands in Gansu (in Chinese). Wetland Sci Manag, 2010, 6: 2926-2939

$39 \mathrm{Wu}$ Y H. Research on Poyang Lake National Nature Reserve in Jiangxi (in Chinese). Beijing: China Forestry Press, 2004

40 State Forest Administration. Chinese Wetland Protection Motion Plan (in Chinese). Beijing: China Forestry Publishing House, 2000

41 Jiang W H, Huang L X, Yu D P. Status and solution of the ex-situ conservation Yangtze Finless porpoise in Tongling Freshwater porpoise national nature reserve (in Chinese). J Hydroecol, 2010, 3: $109-112$

42 Wu X B, Gu C M, Zhu J L, et al. Comprehensive Research on Alligator Sinensis National Nature Reserve in Anhui (in Chinese). Hefei: University of Technology Publishing House, 2008

43 Guo B S, Zhang G H. Present status of resources in Heilongjiang Naolihe national nature reserve and conservation strategy (in Chinese). Chin J Wildlife, 2006, 27: 21-22

44 He B Y, Fan H Q, Wang M. Species diversity in mangrove wetlands of China and its causation analyses (in Chinese). Acta Ecol Sin, 2007, 27: 4859-4870

45 Qu J S. The Comprehensive Management of Mangrove Resources in Leizhou Peninsula (in Chinese). Guangzhou: Guangdong Science and Technology Publishing House, 2006

46 Long D. The water transfer were implement for Albea by Xinjiang authorities more than millions cubic meter (in Chinese). Water Resour Protect, 2008, 24: 75
47 Su Y J, Zhang Z H, Bao A M. Degeneration of the ecological environment in the Ebinur lake region and the improvement measures (in Chinese). Arid Land Geo Charty, 2002, 25: 143-148

48 Wang X P, Yu S L, Wang Z S. The achievement and prospect of effective management for Dafeng Pere David Deer (Elaphurus davidianus) reserve in Jiangsu Province (in Chinese). Beijing Agric, 2009, 15: 58-64

49 Lu B Z. The artificial feeding of Crested Ibis (Nipponia nippon) (in Chinese). Chin Wildlife, 1989, 10: 23-24, 33

50 Margules C R, Pressey R L. Systematic conservation planning. Nature, 2000, 405: 243-253

51 State Forestry Administration, China. Nature Reserve Terminology LY/T 1685-2007 (in Chinese). Beijing: Standards Press of China, 2008

52 Wang Z L, Wang G X, Chang Q. Evaluation of the wetland ecosystems of the Hongze Lake nature reserve in Jiangsu Province (in Chinese). J Nanjing Norm Univ (Nat Sci), 2006, 29: 115-119

53 Deng M L, Tian K, Yang Y X, et al. Variation of landscape of the RuoErgai national reserve of plateau wetland and its driving forces (in Chinese). J Ecol Rural Environ, 2010, 26: 58-62

54 Xiao D N, Li X W, Wang L P. Landscape dynamics and sustainable land use of coastal wetlands resources in Liaohe delta (in Chinese). Resour Sci, 2001, 20: 31-36

55 Halpern B S, Walbridge S, Selkoe K A. A global map of human impact on marine ecosystems. Science, 2008, 319: 948-952

Open Access This article is distributed under the terms of the Creative Commons Attribution License which permits any use, distribution, and reproduction in any medium, provided the original author(s) and source are credited. 